\title{
Differentiated Thyroid Gland Carcinoma Under 45 Years AJCC v7 Stage
}

National Cancer Institute

\section{Source}

National Cancer Institute. Differentiated Thyroid Gland Carcinoma Under 45 Years A/CC v7 Stage. NCl Thesaurus. Code C140961.

A differentiated thyroid gland carcinoma stage for patients under 45 years of age defined according to the AJCC 7th edition criteria. 